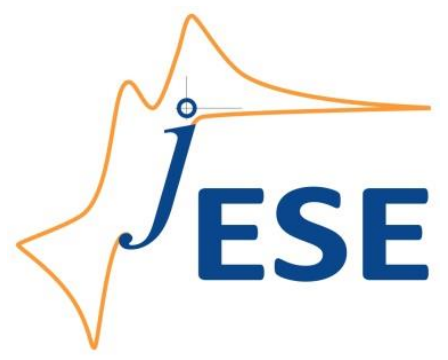

Open Access : : ISSN 1847-9286

www.jESE-online.org

Original scientific paper

\title{
Cyclic voltammetric study of tin hexacyanoferrate for aqueous battery applications
}

\author{
Denys Gromadskyi ${ }^{\bowtie}$, Volodymyr Chervoniuk, Sviatoslav Kirillov \\ Joint Department of Electrochemical Energy Systems, 38A Vernadsky Ave, 03680 Kyiv, Ukraine \\ ${ }^{\otimes}$ Corresponding author: d.gromadskyi@gmail.com; Tel.: +380936726654
}

Received: April 28, 2016; Revised: June 30, 2016; Accepted: July 7, 2016

\begin{abstract}
A hybrid composite containing 65 mass \% of tin hexacyanoferrate mixed with 35 mass \% of carbon nanotubes has been synthesized and its electrochemical behavior as a negative electrode in alkali metal-ion batteries has been studied in $1 \mathrm{~mol} \mathrm{~L}^{-1}$ aqueous solution of sodium sulfate. The specific capacity of pure tin hexacyanoferrate is $58 \mathrm{mAh}^{-1}$, whereas the specific capacity normalized per total electrode mass of the composite studied reaches $34 \mathrm{mAh} \mathrm{g}^{-1}$. The estimated maximal specific power of an aqueous alkali-metal ion battery with a tin hexacyanoferrate electrode is ca. $3.6 \mathrm{~kW} \mathrm{~kg}^{-1}$ being comparable to characteristics of industrial electric double-layer capacitors. The maximal specific energy accumulated by this battery may reach $25.6 \mathrm{Wh} \mathrm{kg}^{-1}$ at least three times exceeding the specific energy for supercapacitors.
\end{abstract}

\section{Keywords}

Aqueous alkali-metal-ion battery; Tin hexacyanoferrate-based composite

\section{Introduction}

Nowadays, the list of electrochemical energy storage devices is quite wide, from electric doublelayer capacitors (the so-called supercapacitors) to various rechargeable batteries (lead-acid, lithiumion and others). Their specific energy and power characteristics significantly vary depending on electrode materials, electrolyte compositions, etc. Supercapacitors demonstrate very high specific power values (up to $6 \mathrm{~kW} \mathrm{~kg}^{-1}$ at $95 \%$ efficiency) but their specific energy is immeasurably low compared to any commercially available battery (1-8 $\left.\mathrm{Wh} \mathrm{kg}^{-1} \mathrm{vs} .26-170 \mathrm{Wh} \mathrm{kg}^{-1}\right)[1,2]$.

In recent years, alkali metal-ion batteries, supercapacitors and their hybrids with neutral aqueous electrolytes gain popularity due to their relatively low cost, fire safety and environmental friendliness as opposed to devices with nonaqueous organic solutions which decompose under 
applied voltage at the presence of a small amount of water impurity and, inter alia, may provoke the corrosion of metallic cell components [3-7]. As electrode materials for the aqueous rechargeable batteries, multivalent metal complexes (e.g. barium, cobalt, copper, iron, manganese, nickel, titanium and zinc hexacyanoferrates) [8-15] are commonly utilized. All these compounds having a perovskite-like structure similar to the Prussian blue $\left(A_{x} M_{y}\left[F e(C N)_{6}\right)\right.$, where $A$ is an alkali metal and $M$ is a multivalent metal) are good hosts for alkali and alkaline earth ions [16]. Their electrochemical properties arise from the process of alkali metal ion intercalation/deintercalation [17]:

$$
\mathrm{M}_{\mathrm{y}}\left[\mathrm{Fe}(\mathrm{CN})_{6}\right]+\mathrm{xA}^{+}+\mathrm{xe}^{-} \leftrightarrow \mathrm{A}_{\mathrm{x}} \mathrm{M}_{\mathrm{y}}\left[\mathrm{Fe}(\mathrm{CN})_{6}\right]
$$

Hexacyanoferrate anion is relatively low-toxic $\left(\mathrm{LD}_{50}\right.$ oral-rat is $\left.1600 \mathrm{mg} \mathrm{kg}^{-1}\right)$ [18] because it does not tend to release free cyanide, and the total toxicity of a salt should be defined by the harmfulness of the multivalent metal. If the data on lethal doses ( $L D_{50}$, oral-rat) and prices for raw materials used for the synthesis of hexacyanoferrates (mainly nitrates and chlorides of reagent grade or p.a. quality) are compared, Table 1, one can see that tin chloride has a low value of $\mathrm{LD}_{50}$ and is quite inexpensive $[18,19]$. This makes tin hexacyanoferrate (SnHCF) an interesting candidate for electrochemical studies. Its theoretical specific capacity $Q_{\text {sp.(theor.) }}$ in the case of insertion/deinsertion of sodium ion,

$$
\mathrm{Sn}_{1.5}\left[\mathrm{Fe}^{\prime \prime \prime}(\mathrm{CN})_{6}\right]+\mathrm{Na}^{+}+\mathrm{e}^{-} \leftrightarrow \mathrm{NaSn}_{1.5}\left[\mathrm{Fe}^{\prime \prime}(\mathrm{CN})_{6}\right]
$$

calculated as

$$
Q_{\text {sp.(theor.) }}=\frac{n F}{M}
$$

equals to $64.9 \mathrm{mAh} \mathrm{g}^{-1}$. In Eq. (3), $n$ is the number of electrons taking part in the electrode halfreaction, $F=26801 \mathrm{mAh} \mathrm{mol}^{-1}$ is the Faraday constant, and $M$ is the molecular mass of $\mathrm{NaSn}_{1.5}\left[\mathrm{Fe}(\mathrm{CN})_{6}\right]$.

Table 1 Toxicity and cost of some multivalent metal chlorides and nitrates.

Chlorides

\begin{tabular}{cccccc|c||c} 
& $\mathrm{BaCl}_{2}$ & $\mathrm{CoCl}_{2}$ & $\mathrm{CuCl}_{2}$ & $\mathrm{MnCl}_{2}$ & $\mathrm{NiCl}_{2}$ & $\mathrm{SnCl}_{2}$ & $\mathrm{ZnCl}_{2}$ \\
\hline $\mathrm{LD}_{50}, \mathrm{mg} \mathrm{kg}^{-1}$ & 118 & 80 & 584 & 1484 & 105 & 700 & 350 \\
\hline Price, $€ \mathrm{~kg}^{-1}$ & 45 & 1272 & 174 & 199 & 904 & 148 & 122 \\
\hline & $\mathrm{8}\left(\mathrm{NO}_{3}\right)_{2}$ & $\mathrm{Co}\left(\mathrm{NO}_{3}\right)_{2}$ & $\mathrm{Cu}\left(\mathrm{NO}_{3}\right)_{2}$ & $\mathrm{Mn}\left(\mathrm{NO}_{3}\right)_{2}$ & $\mathrm{Ni}\left(\mathrm{NO}_{3}\right)_{2}$ & $\mathrm{Sn}\left(\mathrm{NO}_{3}\right)_{2}$ & $\mathrm{Zn}\left(\mathrm{NO}_{3}\right)_{2}$ \\
\hline $\mathrm{LD}_{50}, \mathrm{mg} \mathrm{kg}^{-1}$ & 355 & 691 & 794 & 300 & 1620 & $\mathrm{~N} / \mathrm{A}$ & 1190 \\
\hline Price,$€ \mathrm{~kg}^{-1}$ & 122 & 458 & 300 & 100 & 1590 & $\mathrm{~N} / \mathrm{A}$ & 38 \\
\hline
\end{tabular}

Despite of the large number of publications referred to hexacyanoferrate-based batteries no research works exist directed towards the use of SnHCF in energy storage applications, although it serves as a material for electrochemical sensors [20]. This paper aims at filling this gap, i.e. at exploring potentialities of a SnHCF based composite as an electrode material for aqueous alkali-ion batteries. 


\section{Experimental}

\section{Composite synthesis}

A composite containing SnHCF and multi-walled carbon nanotubes (CNTs) as a conductive additive was synthesized via room-temperature precipitation technique according to the following equation,

$$
3 \mathrm{SnCl}_{2}+2 \mathrm{~K}_{3}\left[\mathrm{Fe}(\mathrm{CN})_{6}\right]=2 \mathrm{Sn}_{1.5}\left[\mathrm{Fe}(\mathrm{CN})_{6}\right]+6 \mathrm{KCl}
$$

FloTube ${ }^{\mathrm{TM}} 9000$ CNTs from C-Nano were treated in nitric-sulfuric acid mixture as proposed in Ref. [21], dispersed in water, and then homogenized by a mechanical stirrer for $15 \mathrm{~min}$. Tin chloride dihydrate (reagent grade, ReaKhim) was added into the reaction vessel and mixed together for next $15 \mathrm{~min}$. After that, the $0.3 \mathrm{~mol} \mathrm{~L}^{-1}$ solution of potassium hexacyanoferrate (reagent grade, ReaKhim) was added dropwise to avoid fast precipitation and coagulation of SnHCF particles. A SnHCF-CNT suspension was stirred for $1 \mathrm{~h}$, filtered, washed with deionized water to neutral $\mathrm{pH}$ and dried at 80 ${ }^{\circ} \mathrm{C}$ for $12 \mathrm{~h}$. It should be noted that the amount of CNTs in the SnHCF/CNT composite was varied from 20 to 80 mass $\%$.

\section{Electrode preparation and characterization}

In order to prepare the electrodes a SnHCF/CNT composite was homogenized in ethanol where polytetrafluoroethylene (60 mass \% dispersion in water, Sigma Aldrich) as a binding agent was added in advance. The mass ratio of the SnHCF/CNT composite and the polytetrafluoroethylene binder was 9 to 1. Pre-electrode slurries were formed by manual mixing in a mortar and alcohol evaporation. Ready-to-use electrodes were obtained after densification by rolling and drying at 80 ${ }^{\circ} \mathrm{C}$ for $12 \mathrm{~h}$. Their porosity analysis was performed at $77 \mathrm{~K}$ by means of Quantachrome ${ }^{\circledR}$ Autosorb Station 3.

\section{Cell assembling and electrochemical testing}

Electrochemical measurements were carried out in a flat three-electrode cell by means of cyclic voltammetric technique on a home-made potentiostat at room temperature. The working electrode was the SnHCF/CNT composite with binding agent (mass $2 \mathrm{mg}$, geometric surface area $0.09 \mathrm{~cm}^{2}$ ). The counter electrode with the geometric surface area of $0.5 \mathrm{~cm}^{2}$ was made of a commercial activated carbon (Kuraray YP50F). These electrodes were separated by two layers of a porous paper membrane (TF4030, Nippon Kodoshi), and a silver sulfate reference electrode fabricated as described in Ref. [22] was located between them. Its potential was $+0.137 \mathrm{~V} \mathrm{vs.} \mathrm{Ag} / \mathrm{AgCl}$ at $25^{\circ} \mathrm{C}$. After assembling, the cell was impregnated by an electrolyte, $1 \mathrm{~mol} \mathrm{~L}^{-1} \mathrm{Na}_{2} \mathrm{SO}_{4}$ aqueous solution.

Cyclic voltammetric testing is suitable for determining key characteristics of any energy storage material, namely its operation potential range, reversibility of charge/discharge processes as well as specific capacity [23]. The latter was calculated as

$$
Q_{\text {sp. }}=\frac{I \Delta U}{3.6 \times v m}
$$

where $Q_{\text {sp. }}$ is the specific capacity $\left(\mathrm{mAh} \mathrm{g}^{-1}\right), l$ is the current (A), $\Delta U$ is the operating potential range $(\mathrm{V}), v$ is the scan rate $\left(\mathrm{V} \mathrm{s}^{-1}\right)$ and $m$ is the electrode mass.

\section{Results and discussion}

The electrochemical behavior of SnHCF-based electrodes depending on the CNT content is shown in Fig. 1. Cyclic voltammograms (CVs) demonstrate cathodic and anodic peaks characteristic of 
electrodes where reversible or quasi-reversible electrochemical reactions take place. Adding CNTs leads to changing the profile of CV making it typical for electrodes with electric double-layer capacitance.

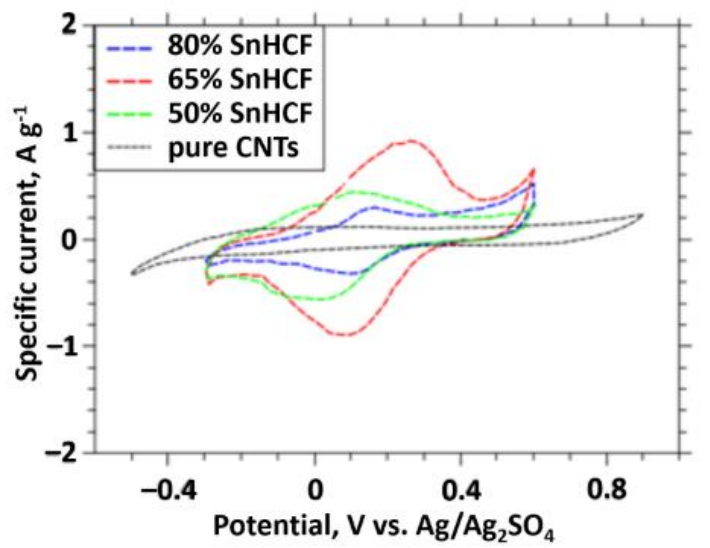

Fig. 1. CVs of SnHCF-based electrodes containing different amount of CNTs recorded at $5 \mathrm{mV} \mathrm{s} \mathrm{s}^{-1}$.

The heights of the peaks responsible for the intercalation/deintercalation of $\mathrm{Na}^{+}$ion into/from the SnHCF structure are different. This means that respective specific capacities are also different and, moreover, non-linearly vary with the SnHCF/CNT ratio. Upon growing the amount of CNTs the specific capacity increases rapidly reaching a maximal value $\left(\sim 45 \mathrm{mAh} \mathrm{g}^{-1}\right)$ at 35 mass \% of CNTs and then decreases. Such behavior presumably reflects the contribution of CNTs to the structure formation of the composites. CNTs not only play the role of a conductive additive; they create a structured framework facilitating the access of ions to electroactive hexacyanoferrate species deposited in mesopores with pore radii greater than $12 \mathrm{~nm}$. This is seen from Fig. 2(a) where pore size distributions calculated according to the density functional theory (DFT) is shown. Besides, SnHCF-based composites have a slightly higher volume $V$ of micropores of about $1 \mathrm{~nm}$ radii $r$ than CNTs possibly due to oxidizing the CNT surface by potassium hexacyanoferrate. Similar behavior is observable in Fig. 2(b) for pore size distributions obtained by the Barrett-Joyner-Halenda (BJH) method, which is less sensitive to microporosity being better suitable for mesoporous materials.

a

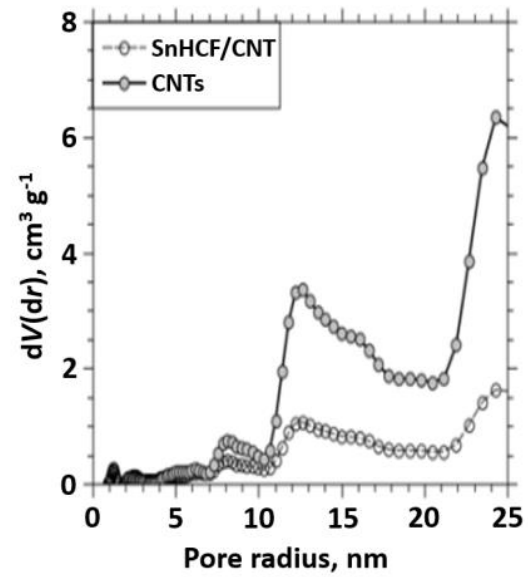

b

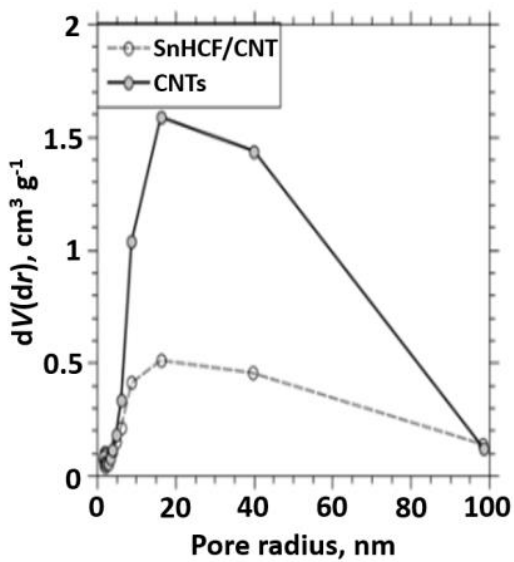

Fig. 2. (a) Pore size distributions for SnHCF electrode with 35 mass \% CNT and pure CNT electrode calculated by means of (a) DFT and (b) BJH techniques.

As the SnHCF-based material containing 35 mass \% of CNTs demonstrates the best electrochemical performance, all following experiments were conducted with it. It should be also mentioned that in performance estimates, some authors account only for the mass of the electroactive material 
and ignore the masses of a conductive additive and a binder [24-26]. In this work, we prefer to operate with the mass of the electrode as a whole since just this value is of practical importance. The specific capacity of the electrode material without the contribution of CNTs and polytetrafluoroethylene can be calculated via division by 0.585 in accord with the mass ratio of electrode components (see Subsections 1 and 2 in Experimental). This gives $Q_{\text {sp. }}$ of about $77 \mathrm{mAh} \mathrm{g}^{-1}$, while the specific capacity ${ }^{1}$ of other insoluble hexacyanoferrates in aqueous electrolytes varies from 36 to $59 \mathrm{mAh} \mathrm{g}^{-1}$ for individual compounds $[10,15,26]$. The $Q_{\mathrm{sp}}$. value obtained is $12 \%$ higher than the theoretical one $\left(64.9 \mathrm{mAh} \mathrm{g}^{-1}\right)$, probably due to the impact of unwanted faradaic side processes (e.g. the decomposition of electrode and/or electrolyte components). Due to this fact in what follows we confined ourselves with a narrower potential range $(-0.25 \ldots+0.50 \mathrm{~V})$.

The CV curves demonstrate a significant dependence on the scan rate, Fig. 3(a), and respective peak heights linearly vary with the square root of the scan rate, Fig. 3(b). This indicates the diffusion control of the $\mathrm{Na}^{+}$intercalation/deintercalation upon the charge/discharge of the SnHCF-based electrode. An analysis of the CV for the SnHCF-based electrode at the slowest scan rate $\left(5 \mathrm{mV} \mathrm{s}^{-1}\right)$ shown in Fig. 4 gives the peak height ratio $I_{a} / I_{c}$ of almost unity characterizing the electrochemical process as a reversible one in spite of the deviation of the peak shift $U_{a} / U_{c}$ from the theoretical value of $59 \mathrm{mV}$ that may be caused by interactions between intercalated species as proposed by Laviron [28].

a

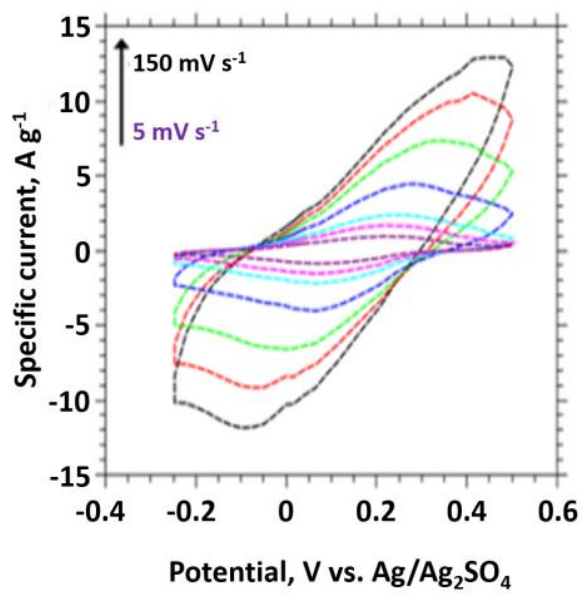

b

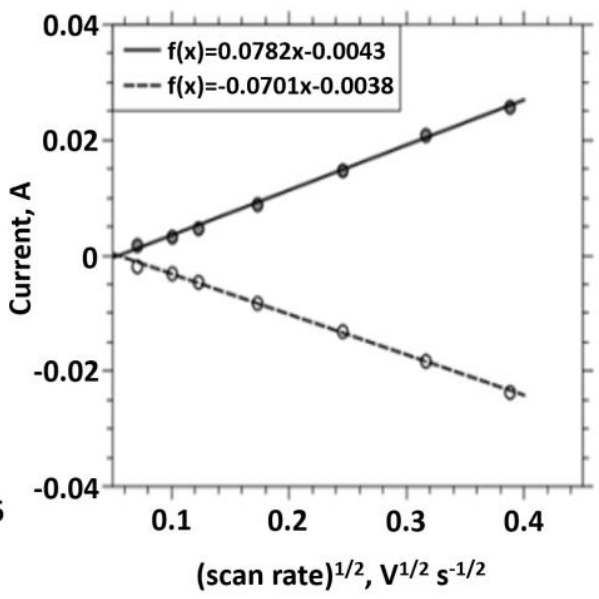

Fig. 3 (a) CVs of SnHCF-based electrode recorded at different scan rates, and (b) dependence of anodic (filled circles) and cathodic (empty circles) peak current on the square root of scan rate for this electrode.

Diffusion coefficients $D$ for $\mathrm{Na}^{+}$cation have been determined via the Randles-Ševčik equation [29]

$$
I_{p}=2.69 \times 10^{5} n^{3 / 2} A D^{1 / 2} C v^{1 / 2}
$$

where $I_{p}$ is the anodic or cathodic peak current $(A), n$ is the number of electrons taking part in the electrode half-reaction; $A$ is the geometric surface area of the electrode $\left(\mathrm{cm}^{2}\right), C$ is the concentration of $\mathrm{Na}^{+}$ions in the electrolyte solution $\left.(\mathrm{mol} \mathrm{cm})^{-3}\right) ; v$ is the scan rate $\left(\mathrm{V} \mathrm{s}^{-1}\right)$. They are $2.1 \cdot 10^{-6} \mathrm{~cm}^{2} \mathrm{~s}^{-1}$ and $2.6 \cdot 10^{-6} \mathrm{~cm}^{2} \mathrm{~s}^{-1}$ for the intercalation and deintercalation processes, respectively.

\footnotetext{
${ }^{1}$ In some articles authors consider insoluble hexacyanoferrates, which are typical battery-type materials, as supercapacitor-type ones. Consequently, they characterize them by specific capacitances instead of specific capacities that is fundamentally flawed as described in Ref. [27]. Therefore, in order to compare our data with results obtained by other researchers we transfer the specific capacitance into the specific capacity through its multiplication by operating potential range and division by 3.6.
} 


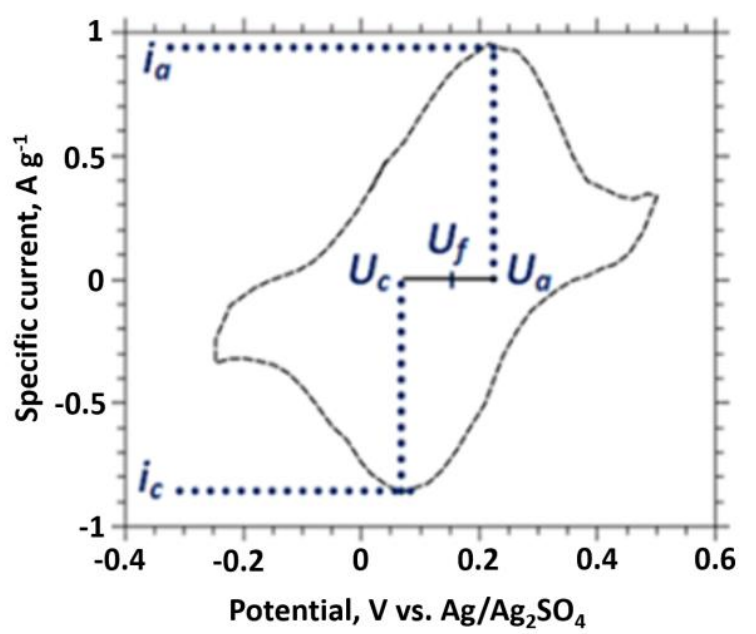

Fig. 4. CV of SnHCF-based electrode recorded at $5 \mathrm{mV} \mathrm{s}^{-1}$

The $D$ values obtained are significantly higher than diffusion coefficients in transition metal oxides commonly employed as electrodes in 'traditional' lithium-ion batteries, being rather comparable with effective diffusion coefficients obtained in supercapacitor electrodes produced from commercial activated carbons [30-33]. Such behavior can be explained by an effect of CNTs on the structure of the synthesized composite, where SnHCF particles are located in $12 \mathrm{~nm}$ pores formed by a CNT network. These nanosized particles are better accessible to electrolyte, and all advantages of finely subdivided electrode materials [34] are applicable to them.

The maximal specific capacity of the composite electrode $\left(34 \mathrm{mAh} \mathrm{g}^{-1}\right)$ is observed at $5 \mathrm{mV} \mathrm{s}^{-1}$, Fig. 5. Using a 0.585 factor as described above, the capacity related to the mass of neat SnHCF is determined as $58 \mathrm{mAh} \cdot \mathrm{g}^{-1}$ thus representing $89 \%$ of the theoretical value.

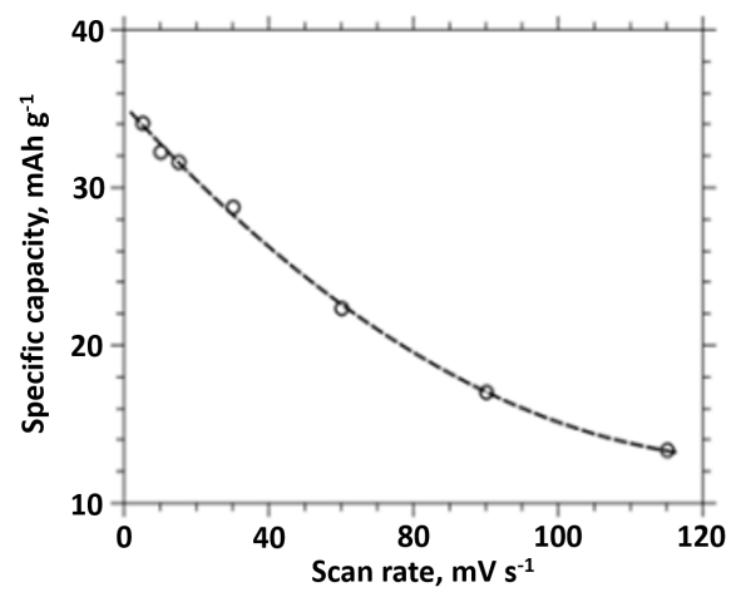

Fig. 5. Dependence of specific capacity of SnHCF-based electrode on the scan rate

Another important requirement for energy storage devices in addition to high specific capacity is their charge/discharge cycling stability. According to data shown in Fig. 6 the SnHCF-based electrode demonstrates an excellent cycling behavior. No capacity decrease is observed after 500 charge/discharge cycles. Furthermore, $Q_{\text {sp. }}$ even increases a little (by $\sim 5 \%$ ) at the first cycles, possibly due to deeper ion intercalation into the hexacyanoferrate structure (pretreatment), and becomes stable reaching the value of $23 \mathrm{mAh} \mathrm{g}^{-1}$. This is confirmed by changes in the anodic and cathodic peak heights collected in Table 2, which are leveling on growing the cycle number. The insignificant drift of the formal potential on cycling $\left(10^{-5} \mathrm{~V}\right.$ cycle $\left.{ }^{-1}\right)$ should also be considered as an additional verification of the good reversibility of the electrochemical system studied. Furthermore, 
it is asserted [35] that the constancy of the formal potential signifies right mass balancing of the negative and positive electrodes in the cell.

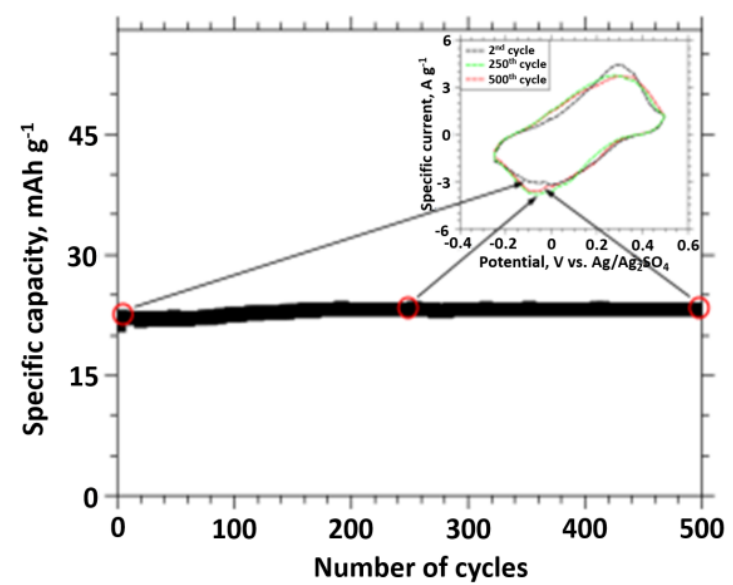

Fig. 6. Changes in the specific capacity of SnHCF-based electrode during voltammetric cycling at $50 \mathrm{mV} \mathrm{s}^{-1}$

Table 2. CV parameters of SnHCF-based electrode obtained from cyclic voltammograms given in Fig. 6 .

\begin{tabular}{cccccccc}
\hline Cycle number & $i_{a}, \mathrm{~A} \mathrm{~g}^{-1}$ & $I_{c}, \mathrm{~A} \mathrm{~g}^{-1}$ & $I_{\mathrm{a}} / I_{c}$ & $U_{a}, \mathrm{~V}$ & $U_{c}, \mathrm{~V}$ & $U_{f}, \mathrm{~V}$ & $Q_{\text {sp. }} \mathrm{mAh} \mathrm{g}^{-1}$ \\
\hline 2 & 4.43 & 3.19 & 1.39 & 0.28 & 0.0024 & 0.141 & 22.0 \\
\hline 250 & 3.68 & 3.80 & 0.97 & 0.29 & -0.0050 & 0.143 & 23.3 \\
\hline 500 & 3.70 & 3.80 & 0.97 & 0.30 & -0.0075 & 0.146 & 23.3 \\
\hline
\end{tabular}

Using the data from Fig. 5 recalculated into the specific energy $E_{\text {sp. }}$ and power $P_{\text {sp. }}$ by means of Eqs. 7 and 8, one can build the so-called Ragone plot (Fig. 7), which helps to better understand the application field of the synthesized composite [36],

$$
\begin{gathered}
E_{\text {sp. }}=Q_{\text {sp. }} \Delta U \\
P_{\text {sp. }}=\frac{E_{\text {sp. }}}{\tau}
\end{gathered}
$$

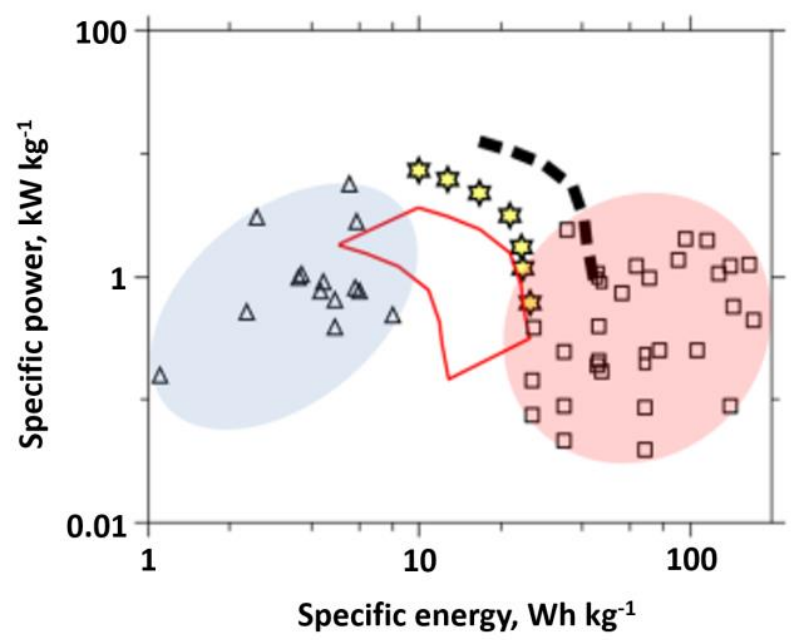

Fig. 7. Ragone plot for pure SnHCF (dashed line), SnHCF-based electrode (stars), and a 'virtual' aqueous alkali metal-ion battery with SnHCF-based electrode (an area within the red polygon) in comparison with industrial supercapacitors (triangles limited by a blue colored area) and various rechargeable batteries (squares limited by a pink colored area) [1,2].

In Eq. (8), $\tau$ is the time of charging or discharging the electrode in $\mathrm{h}$. 
In Fig. 7 we also plot the data on specific power and energy recalculated per mass of the pure electroactive material as well as per the total mass of a battery with the SnHCF-based composite as a negative electrode and additional cell elements (our approach to this calculation is given in footnote ${ }^{2}$ ). This clearly demonstrates how the characteristics are changing depending on the way of their presentation (material, electrode or device). As has been already mentioned, 'the truest' data are those normalized per electrode mass. Despite of fundamental differences in the charge storage mechanism (intercalation/deintercalation instead of adsorption/desorption), the SnHCF-based electrodes and hence energy accumulating devices with such electrodes demonstrate the specific power comparable with electric double-layer capacitors, and their specific energy values are close to lead-acid batteries. For instance, such composite electrodes can be charged up to half-capacity in a fast mode (by 7.5 seconds) with specific power of $6.1 \mathrm{~kW} \mathrm{~kg}^{-1}$, while in order to charge them fully (up to $25.6 \mathrm{Wh} \mathrm{kg}^{-1}$ ), less than 3 min is needed. We expect that a battery pack with SnHCF/CNT electrodes will be able to achieve the specific power and energy of (1.8-3.6) $\mathrm{kW} \mathrm{kg}^{-1}$ and (12.8-25.6) $\mathrm{Wh} \mathrm{kg}^{-1}$, respectively.

The formal potentials of some multivalent metal hexacyanoferrates taken from literature sources [40-50] are collected in Fig. 8 where they are contingently divided into two groups representing negative and positive electrodes. The relatively low formal potential $U_{f}$ of the SnHCF-based electrode determined as $U_{f}=\left(U_{a}+U_{b}\right) / 2\left(+0.143 \mathrm{~V} v\right.$ s. $\mathrm{Ag} / \mathrm{Ag}_{2} \mathrm{SO}_{4}$ or ca. $+0.28 \mathrm{~V} v$ s. $\left.\mathrm{Ag} / \mathrm{AgCl}\right)$ signifies an opportunity of employing the synthesized composite as a negative electrode (anode) for aqueous alkali metal-ion batteries. The best counter electrode for SnHCF that allows for getting a maximal operating voltage for a battery is VHCF and InHCF, but the extra-high cost of vanadium and indium raw materials makes CuHCF preferable for large-scale manufacturing [19]. Our further efforts will be directed towards both cathode and anode HCF materials. SnHCF-based composites mixed with other multivalent metal hexacyanoferrates (e.g. FeHCF and/or TiHCF due to their low $U_{f}$ values) would be of great interest as such mixtures have been shown to have much higher specific capacity compared to the individual components $[25,51]$.

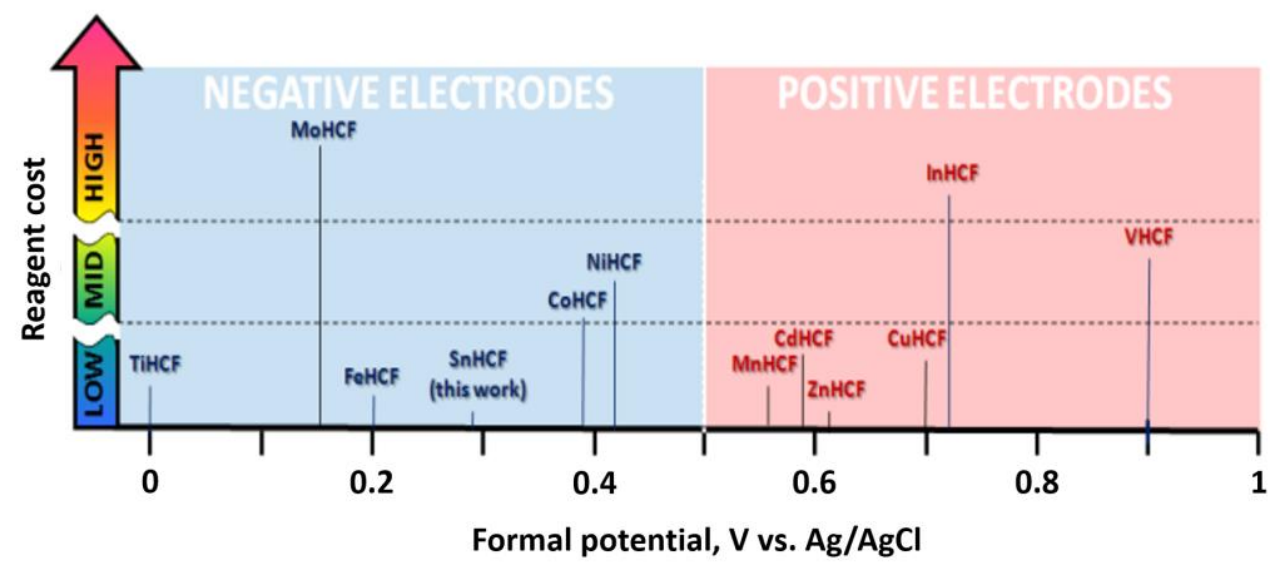

Fig. 8 Formal potential of SnHCF-based electrode compared with formal potentials of other hexacyanoferrates in the $\mathrm{Ag} / \mathrm{AgCl}$ scale.

\footnotetext{
2 Following to this approach the specific power of a single SnHCF-based electrode should be doubled if compared to the specific power of a two-electrode cell, whereas the specific energy remains almost unchanged in the case if the cell is assembled in an anode-limited design and both (negatively and positively charged) electrodes have the same working potential ranges vs. a nominal zero point [37]. Further, in our calculations, we account for the mass of the whole cell, since according to Refs. [38,39], the mass contribution of two electrodes to the total value of specific energy is of about $25-50 \%$.
} 


\section{Conclusions}

A novel SnHCF-CNT composite has been fabricated by means of a room-temperature precipitation technique. The specific capacity of this electrode determined via cyclic voltammetry reaches $34 \mathrm{mAh} \mathrm{g}^{-1}$ at the slowest scan rate. Excellent electrochemical stability during charge/discharge cycling as well as fast ionic diffusion $\left(D \approx 2 \cdot 10^{-6} \mathrm{~cm}^{2} \mathrm{~s}^{-1}\right)$ makes the synthesized SnHCF/CNT composite an attractive electrode material for low-cost and environmental friendly aqueous alkali metal-ion batteries, which can compete with supercapacitors in high-power applications.

\section{References}

[1] A. Burke, Proc. IEEE 95(4) (2007) 806-820.

[2] A. Burke, Int. J. Energy Res. 34 (2010) 133-151.

[3] H. Kim, J. Hong, K. Y. Park, H. Kim, S. W. Kim, K. Kang, Chem. Rev. 114(23) (2014) 1178811827.

[4] A. J. Stevenson, D. G. Gromadskyi, D. Hu, J. Chae, L. Guan, L. Yu L, G. Z. Chen, Supercapattery with hybrids of redox active polymers and nanostructured carbons, in: X.L. Feng (Ed.), Nanocarbons for Advanced Energy Storage, Wiley-VCH, Weinheim, Germany, 2015, pp. 179-210.

[5] D. G. Gromadskyi, J. H. Chae, S. A. Norman, G. Z. Chen, Appl. Energy 159 (2015) 39-50.

[6] D. H. Hromadśkyi, Y. F. Fateev, N. H. Stryzhakova, Y. A. Maletin, Mater. Sci. 46(3) (2010) 412-417.

[7] D. G. Gromadskyi, Y. F. Fateev, Y. A. Maletin, Corros. Sci. 69 (2013) 191-196.

[8] P. Padigi, G. Goncher, D. Evans, R. Solanki, Potassium barium hexacyanoferrate - a potential cathode material for rechargeable calcium ion batteries, J. Power Sources $\mathbf{2 7 3}$ (2015) 460-464.

[9] F. Zhao, Y. Wang, X. Xu, Y. Liu, R. Song, G. Lu, Y. Li, ACS Appl. Mater. Interfaces 6(14) (2014) 11007-11012.

[10] C. D. Wessells, R. A. Huggins, Y. Cui, Nat. Commun. 2 (2011) Article No. 550.

[11] Y. You, X. Yu, Y. Yin, K.W. Nam, Y.G. Guo, Nano Res. 8(1) (2015) 117-128.

[12] L. Wang, Y. Lu, J. Liu, M. Xu, J. Cheng, D. Zhang, J. B. Goodenough, Angew. Chem. Int. Ed. 52 (2013) 1964-1967.

[13] C. D. Wessells, S. V. Peddada, R. A. Huggins, Y. Cui, Nano Lett. 11 (2011) 5121-5425.

[14] M. Xie, Y. Huang, M. Xu, R. Chen, X. Zhang, L. Li, J. Power Sources 302 (2016) 7-12.

[15] H. Lee, Y.I. Kim, J.K. Park, J.W. Choi, Chem. Commun. 48 (2012) 8416-8418.

[16] C. Ling, J. Chen, F. Mizuno, J. Phys. Chem. C. 117 (2013) 21158-21165.

[17] J. Yun, J. Pfisterer, A.S. Bandarenka, Energy Environ. Sci. 9 (2016) 955-961.

[18] MSDS database, URL: http://ccinfoweb.ccohs.ca/msds/search.html (viewed on 10.02.2016).

[19] Sigma Aldrich catalog, URL: http://www.sigmaaldrich.com/catalog/search (viewed on 10.02.2016).

[20] H. Razmi, A. Taghvimi, Int. J. Electrochem. Sci. 5 (2010) 751-762.

[21] M. S. P. Shaffer, X. Fan, A. H. Windle, Carbon 36(11) (1998) 1603-1612.

[22] D. G. Gromadskyi, J. Chem. Sci. 128 (2016) 1011- 1017.

[23] S. Zhang, N. Pan, Adv. Energy Mater. 5(6) (2015) DOI: 10.1002/aenm.201401401.

[24] J. Chen, K. Huang, S. Liu, Electrochem. Commun. 10 (2008) 1851-1855.

[25] Y. Yang, Y. Hao, J. Yuan, L. Niu, F. Xia, Carbon. 84 (2015) 174-184.

[26] Y. Yang, H. Hao, X. Wang, Q. Yan, J. Yuan, Y. Shao, L. Niu, Electrochim. Acta 167 (2015) 364371.

[27] A. Laheäär, P. Przygocki, Q. Abbas, F. Béguin, Electrochem. Commun. 60 (2015) 21-25.

[28] E. Laviron, J. Electroanal. Chem. Interfacial Electrochem. 52 (1974) 395-402. 
[29] P. Zanello, Inorganic electrochemistry: theory, practice and application, Royal Society of Chemistry, Cambridge, UK, 2003, p. 615.

[30] C. K. Park, S. B. Park, S. H. Oh, H. Jang, W. Cho, Bull. Korean Chem. Soc. 32 (2011) 836-840.

[31] H. Hia, L. Lu, G. Ceder, J. Power Sources 159 (2006) 1422-1427.

[32] S. B. Tang, M. O. Lai, L. Lu, Mater. Chem. Phys. 111(1) (2008) 149-153.

[33] Y. Maletin, V. Strelko, N. Stryzhakova, S. Zelinsky, A. B. Rozhenko, D. Gromadsky, V. Volkov, S. Tychina, G. Gozhenko, D. Drobny, Energy Environ. Res. 3 (2013) 156-165.

[34] A. S. Aricó, P. Bruce, B. Scrosati, J.M. Tarascon, W. Schalkwijk, Nat. Mater. 4 (2005) 366377.

[35] Z. G. Dai, C. Peng, J. H. Chae, G. Z. Chen, Sci. Rep. 5 (2015) Article No. 9854.

[36] W. G. Pell, B. E. Conway, J. Power Sources 63 (1996) 255-266.

[37] X. Wu, Y. Cao, X. Ai, J. Qian, H. Yang, Electrochem. Commun. 31 (2013) 145-148.

[38] C. Liu, Z. Yu, D. Neff, A. Zhamu, B.Z. Zhang, Nano Lett. 10 (2010) 4863-4868.

[39] A. Du Pasquier, J. A. Shelburne, I. Plitz, F. Badway, A. S. Gozdz, G. G. Amatucci, Proc. $11^{\text {th }}$ Int. Semin. Double Layer Capacitors and Similar Energy Storage Devices, Deerfield Beach, USA. 2001, pp. 1-10.

[40] Z. Gao, G. Wang, P. Li. Z. Zhao, Electrochim. Acta 36(1) (1991) 147-152.

[41] C. H. Luangdilok, D. J. Arent, A. B. Bocarsly, R. Wood, Langmuir. 8(2) (1992) 650-657.

[42] L. M. Siperko, T. Kuwana, Electrochim. Acta 32(5) (1987) 765-711.

[43] K. Itaya, K. Ataka, S. Toshima, J. Am. Chem. Soc. 104(18) (1982) 4767-4772.

[44] S. Dong, Z. Jin, Electrochim. Acta 34(7) (1989) 963-968.

[45] P. Wang, Z. Jing, W. Zhang, G. Zhu, J. Solid State Electrochem. 5(6) (2001) 369-374.

[46] S. Dong, Z. Jin, J. Electroanal. Chem. 256(1) (1988) 193-198.

[47] M. H. Pournaghi-Azar, H. Razmi-Nerbin, J. Electroanal. Chem. 456(1-2) (1998) 83-90.

[48] M. Jiang, X. Zhou, Z. Zhao, J. Electroanal. Chem. 292(1-2) (1990) 289-296.

[49] S. Dong, F. Li, J. Electroanal. Chem. 210(1) (1986) 31-44.

[50] J. Joseph, H. Gomathi, G. P. Rao, J. Electroanal. Chem. 431(2) (1997) 231-235.

[51] A. Safavi, S. H. Kazemi, H. Kazami, Electrochim. Acta 56 (2011) 9191-9196.

2016 by the authors; licensee IAPC, Zagreb, Croatia. This article is an open-access article distributed under the terms and conditions of the Creative Commons Attribution license (http://creativecommons.org/licenses/by/4.0/) 